\title{
Reef-scale trends in Florida Acropora spp. abundance and the effects of population enhancement
}

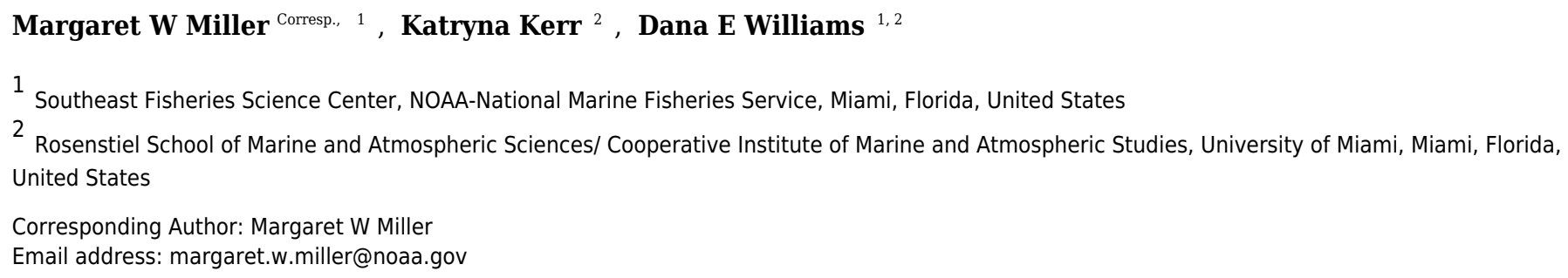

Since the listing of Acropora palmata and A. cervicornis under the U.S. Endangered Species Act in 2006, increasing investments have been made in propagation of listed corals (primarily A. cervicornis, A. palmata to a much lesser extent) in offshore coral nurseries and outplanting cultured fragments to reef habitats. This investment is superimposed over a spatiotemporal patchwork of ongoing disturbances (especially storms, thermal bleaching, and disease) as well as the potential for natural population recovery. In 2014 and 2015, we repeated broad scale (>50 ha), low precision Acropora spp. censuses (i.e., direct observation by snorkelers documented via handheld GPS) originally conducted in appropriate reef habitats during 2005-2007 to evaluate the trajectory of local populations and the effect of population enhancement. Over the decade-long study, A. palmata showed a cumulative proportional decline of $0.4-0.7 x$ in colony density across all sites, despite very low levels of outplanting at some sites. A. cervicornis showed similar proportional declines at sites without outplanting. In contrast, sites that received $A$. cervicornis outplants showed a dramatic increase in density (over 13x). Indeed, change in A. cervicornis colony density was significantly positively correlated with cumulative numbers of outplants across sites. This study documents a substantive reef-scale benefit of Acropora spp. population enhancement in the Florida Keys, when performed at adequate levels, against a backdrop of ongoing population decline. 
1

2

3

4

5

6

7

8

9

10

11

12

13

14

15

16

17

18
Reef-scale trends in Florida Acropora spp. abundance and the effects of population enhancement

Miller $\mathrm{MW}^{1 *}$, Kerr KA ${ }^{2}$, Williams $\mathrm{DE}^{1,2}$

1. NOAA National Marine Fisheries Service, Southeast Fisheries Science Center, 75 Virginia Beach Dr. Miami FL 33140 USA

2. Cooperative Institute for Marine and Atmospheric Studies, Rosenstiel School of Marine and Atmospheric Science, University of Miami, 4600 Rickenbacker Cswy. Miami FL 33149 USA

*Corresponding Author: Margaret.w.miller@noaa.gov 
19 ABSTRACT: Since the listing of Acropora palmata and A. cervicornis under the U.S. Endangered Species Act in 2006, increasing investments have been made in propagation of listed corals

21 (primarily A. cervicornis, A. palmata to a much lesser extent) in offshore coral nurseries and outplanting cultured fragments to reef habitats. This investment is superimposed over a spatiotemporal patchwork of ongoing disturbances (especially storms, thermal bleaching, and disease) as well as the potential for natural population recovery. In 2014 and 2015, we repeated broad scale ( $>50$ ha), low precision Acropora spp. censuses (i.e., direct observation by snorkelers documented via handheld GPS) originally conducted in appropriate reef habitats during 2005-2007 to evaluate the trajectory of local populations and the effect of population enhancement. Over the decade-long study, A. palmata showed a cumulative proportional decline of $0.4-0.7 x$ in colony density across all sites, despite very low levels of outplanting at some sites. A. cervicornis showed similar proportional declines at sites without outplanting. In contrast, sites that received $A$. cervicornis outplants showed a dramatic increase in density (over 13x). Indeed, change in A. cervicornis colony density was significantly positively correlated with cumulative numbers of outplants across sites. This study documents a substantive reef-scale benefit of Acropora spp. population enhancement in the Florida Keys, when performed at adequate levels, against a backdrop of ongoing population decline. 


\section{INTRODUCTION:}

Caribbean coral reefs are home to two species of fast-growing, habitat-forming species of Acropora spp. corals; staghorn (A. cervicornis) and elkhorn (A. palmata). Both are listed as Critically Endangered by IUCN and threatened under the US Endangered Species Act (ESA). Their endangered status accrues from a litany of factors which have caused extensive mortality combined with inadequate recruitment to sustain populations throughout their range (Acropora Biological Review Team 2005; Aronson \& Precht 2001; Bright et al. 2013). ESA listing carries a legal mandate to 'recover' imperiled species. The Recovery Plan for A. palmata and A. cervicornis (NMFS 2015) describes the need for ongoing monitoring and evaluation to track the status of populations, as well as the need to curb ongoing threats (e.g., disease, land-based sources of pollution, and thermal stress due to global climate change) and implement proactive population enhancement measures to jumpstart population recovery (NMFS 2015). Growing effort has been dedicated to implementing population enhancement throughout the Caribbean (Young et al. 2012), largely following the 'coral gardening' model (Epstein et al. 2003; Rinkevich 2015).

As Acropora population enhancement effort has grown, substantial management and planning effort has been invested into developing risk-averse strategies. These strategies include 1. emphasis on in situ (versus land-based) culture, 2. dispersing individual field nursery operations to limit the geographic distance from which source stocks are drawn and propagated fragments are outplanted, and 3. maximizing and tracking the genotypic diversity of cultured stocks. Acropora spp. are propagated via fragmentation from locally-collected stocks in offshore field nurseries, grown to a viable size and then outplanted to reef habitats with the 
60

61

62

63

64

65

goal of re-creating sustainable population patches which can serve as larval sources to jumpstart population recovery on a broader scale. Common practices and details of implementation are described in Johnson et al. (2011).

3

Unfortunately, cultured Acropora fragments often behave like their wild counterparts in Caribbean reef communities as they are subject to ongoing chronic and acute stressors, often manifesting substantial mortality in the same pattern as the background population (Miller et al. 2014; Schopmeyer \& Lirman 2015). Critics of population enhancement maintain that potentially high levels of mortality would preclude any long term benefit to population recovery, and that high cost implies that the scale of effect (e.g., area of reef) will remain trivial. Substantial published work has documented the remarkable success of these field nursery culture efforts (Griffin et al. 2012; Lirman et al. 2014; Lirman et al. 2010; Lohr et al. 2015) as well as the short term fate of individual outplanted colonies (Griffin et al. 2015a; MercadoMolina et al. 2015). These evaluations are based on tractable observations and measurements of individual tagged colonies at a few sites over one to a few years. There is a much greater challenge in tracking Acropora spp. colony abundance at the meso-scale (100's $\mathrm{m}^{2}$ to hectares) due to fragmentation, displacement, and partial mortality. Consequently, there is little information available to aid in evaluating the potential for active population enhancement to 'move the needle' in affecting reef-scale population trajectories of Caribbean Acropora spp. In this study, we used a broad scale, low-precision census technique (direct observation by snorkelers documented via handheld GPS; Devine et al. 2005; Walker et al. 2012) to further this evaluation goal by documenting both the long term $(2005-2015)$ reef-scale trajectory of Florida Keys Acropora populations undergoing ongoing acute and chronic disturbances as well 
82 as whether these trajectories are influenced by population enhancement effort. The acute

83 disturbances affecting these populations included multiple tropical storms $(2005,2008,2012)$, a

84 severe cold thermal event in 2010, mild bleaching in 2011, and a severe warm thermal mass

85 bleaching event in 2014 as well as chronic and substantial effects of predation and disease

86 (Williams \& Miller 2012).

A conservation organization in the upper Florida Keys (Coral Restoration Foundation, CRF) has been propagating and outplanting A. cervicornis since 2003 (substantial numbers since 2011) and A. palmata since 2012 (substantial numbers since 2014, Suppl. Table 1), although the number of outplants placed on the reef has varied greatly over time according to the factors such as permitting restrictions, damaging storms which required time for recovery of nursery infrastructure and cultured stocks, and funding levels. This sustained effort combined with the availability of historic census information from a range of reef sites in the upper Florida Keys provides a novel opportunity to evaluate potential reef-scale effects of Acropora spp. population enhancement against a backdrop of ongoing chronic and acute disturbances in the reef environment. We compared trajectories of Acropora spp. density at reef areas which had versus had not received population enhancement efforts over appropriate time frames to evaluate the reef-scale effect of enhancement.

METHODS:

Sites targeted for this study were chosen in 2005, prior to the onset of substantial

102 population enhancement efforts. Habitat maps (as described in Lidz et al. 2006; Marszalek 1977) were used to identify shallow $(<5 \mathrm{~m})$ coral habitat areas in the upper Florida Keys, 
104 spanning between Carysfort reef in the north to Pickles reef in the south (i.e., $25.2^{\circ} \mathrm{N}$ to $24.9^{\circ} \mathrm{N}$

105 latitude). Targeted reef areas were restricted to less than $5 \mathrm{~m}$ depth as observations at deeper

106 depths on snorkel become less reliable. This depth range encompasses the core habitat for $A$.

107 palmata, though $A$. cervicornis traditionally occupies a wider depth range. Most, but not all

108 sites were surveyed once in 2005-7, once in 2013 or 14, and once in 2015 (Suppl. Table 2; Miller

109 2008; Williams 2013). Hence, different numbers of sites are available for different temporal

110 comparisons.

111 Teams of two or three snorkelers addressed each study site with the intent to observe

112 the entire reef surface via swimming sequential, parallel linear transects. The width of each

113 transect was adjusted according to conditions including depth, relief and water visibility, with

114 the intent that the benthos was thoroughly observed with minimal overlap. In practice, this is

115 very challenging to accomplish and enhanced procedures were implemented as the effort

116 progressed to improve the practical coverage, including the visual delineation of the target area

117 (or subset assigned to an individual snorkeler) with weighted dive flags and the use of compasses and pre-agreed headings (generally following the direction of reef spurs) to maintain parallel tracks. In the early censuses, dive scooters (SeaDoo VS Supercharged) were used, but snorkelers performed surveys predominantly under their own power in 2013-15. Each snorkeler towed a handheld GPS unit (Garmin GPS72 in 2005-7; Garmin eTrex20

122 for 20113-15) in a waterproof plastic pouch attached to a floating dive flag. The GPS recorded

123 the 'track' traversed by the snorkeler. When an Acropora spp. colony was encountered, the 124 snorkeler recorded a waypoint on the GPS for each, and recorded the species for each waypoint 125 on a field data sheet. In some cases, A. palmata colonies were observed growing in high 
126 density patches wherein it was not feasible to demarcate individual colonies. In these cases,

127 the snorkeler would swim around the perimeter of the feature and record waypoints along the

128 outline which were designated on the data sheet as a 'thicket'. While it is possible that this

129 qualitative definition may have been applied slightly differently by different observers, the

130 disappearance of known thicket areas (e.g., Grecian Rocks and Watsons reef) at later surveys

131 was verified by multiple observers. The area occupied within this 'thicket' outline was

132 calculated in GIS for each survey and was compared at each site over time. We did not

133 document any analogous 'thickets' for $A$. cervicornis.

134 After each survey was completed, the GPS-recorded track was saved, waypoints and

135 tracks were downloaded to a personal computer, and then exported to a spreadsheet file

136 where the waypoint attributes were entered from the field data sheet. For each study site,

137 maps were created in ArcGIS plotting the colonies and thickets observed for each census year

138 (Fig 1A-1B, Suppl Fig 1). Lastly, the observational paths followed by the surveyors (i.e. the GPS

139 tracks) were imported to each map to depict the area searched. Using the Minimum Bounding

140 Geometry tool, the minimum area covered by the observational path (observed area) was

141 determined for each year*site map.

142 Temporal comparisons were made for two intervals: a long-term interval from the

143 periods 2005-07 (early; e.g., Fig 1A) to 2013-14 (late; Fig 1B); and a short term interval from

144 2013-14 (early; Suppl Fig 1A) to 2015 (late; Suppl Fig 1B). For each site, the early and late maps

145 were merged to make temporal comparisons of reef scale density trends (Fig 1C, Suppl Fig 1C).

146 Each temporal comparison was restricted to congruent observed areas of the reef (i.e., covered

147 by the observational paths in both time points) by clipping the area of comparison to the area 
148 of overlap in the observed area for each year using the Intersect tool. If the congruent area

149 consisted of numerous overlapping polygons, then the Merge Polygon tool was used. Areas

150 outlined as A. palmata 'thicket' were calculated for each survey and the number of colonies in

151 each thicket area was estimated using a standard density estimate of 1 colony per $\mathrm{m}^{2}$ (based on

152 independent field estimates using fixed area belt transects within the Horseshoe reef thicket

153 over four years yielding a mean of $1.01 \pm 0.26$ SD colonies per $\mathrm{m}^{2}$; M.Miller unpublished data).

154 Individual colony waypoints and thicket abundance estimates were summed for each species to

155 obtain the total abundance for each survey year in the overlapping comparison area.

156 Total colony abundance of each species in each year in the congruent search area of

157 reef was converted to density (total number of colonies observed / congruent observed area of

158 reef $\left(m^{2}\right)$ ) to compare between time points (Mann-Whitney Rank Sum tests). For temporal

159 comparisons, the proportional change in density between two time points was calculated. This

160 proportional change in density at each site was calculated for the longest interval observed for

161 each site, as well as the pre- (2005-6 versus 2014) and post-bleaching (2014 versus 2015)

162 intervals. Proportional change in density was annualized by dividing by the number of years

163 between surveys and Mann-Whitney Rank Sum tests were used to test for significant difference

164 between the pre- and post-bleaching intervals.

Information on the total number of coral colonies of each species outplanted to each

censused reef site by year was provided by staff of the Coral Restoration Foundation (J. Levy

167 and K. Ripple; Pers comm; Suppl Table 1). CRF is the only organization undertaking large scale

Acropora spp. population enhancement in the study area (additional nurseries operate and 
170 the longest observed interval for each reef (Suppl. Table 3) was used to correlate the overall

171 impact of population enhancement for $A$. cervicornis as outplanting has been ongoing for this

172 species since 2008 and this enabled the use of information from all sites ( $n=14$, a few of which

173 had not been surveyed in 2013 or 14). However, substantial outplanting was only conducted

174 for A. palmata since 2014 (Suppl Table 1) so the 2014 to 2015 interval only was used to

175 correlate with outplanting effect for this species. For each species, we conducted a Mann-

176 Whitney rank sum test comparing proportional change in colony density between the sites

177 which had and sites which had not received outplants. Also, a simple linear regression was

178 performed for each species between the proportional change in colony density and the

179 cumulative number of outplants among all sites.

180

181

RESULTS:

182

The total surveyed area for each census ranged from 55 to 77 hectares while the congruent observed area of reef for temporal comparisons within each site ranged from 1.6 to

15.5 hectares (Table 1). Acropora palmata thickets were observed at four sites in 2005-7, two

of which had disappeared by 2015 (Fig 2). At these two sites (Grecian Rocks and Watson's

Reef) the aggregation of $A$. palmata colonies in the thicket area had dwindled to where it was

no longer designated a thicket, though a few widely-spaced remnant colonies remained. One

of the other two sites with thickets showed approximately half decline in area, whereas the last palmata thicket area (from $2229 \mathrm{~m}^{2}$ to $713 \mathrm{~m}^{2}$ ) among these four sites. 
192 the absence of outplanting (40\% decline in density for $A$. cervicornis, $70 \%$ decline for $A$.

193 palmata, pooled among 7 or 9 sites respectively; Table 2). When considering trends between

194 the pre- and post-bleaching intervals, A. cervicornis showed a substantial annualized increase in density when averaged across all sites from 2005 to 2014 ( $n=8$, Table 1A, Fig 3A)) with the most dramatic changes occurring at sites receiving outplants (Table 1A). A. cervicornis density increased only slightly on average between 2014 and 2015 (co-incident with a mass thermal bleaching event and a smaller cumulative number of outplants) yielding a significant difference in annualized density change between the two intervals (Mann-Whitney Rank Sum Test p=0.037;

Fig 3A). Meanwhile, A. palmata showed much smaller proportional changes in density substantially negative in the 2005-14 interval and essentially stable in the 2014-15 (bleaching) interval (Fig 3), this difference was not statistically significant (t-test, $p=0.824$ ).

To specifically evaluate the hypothesis that outplanting effort had a significant, these tests were applied to the full interval of observation at each site (2005-2015, n=14 sites, Suppl Table 3) whereas for A. palmata, substantial enhancement effort has only occurred since 2014 so the 2014-2015 interval was used. A Mann-Whitney U-test indicated that sites receiving

A. cervicornis outplants had significantly different change in density than those that did not

$210(p=0.002)$. However, no significant difference occurred for $A$. palmata (corresponding to a

211 much smaller cumulative number of outplants, Table 1). Simple linear regression showed a

212 strong and highly significant relationship between change in A. cervicornis colony density and 
213 cumulative number of outplants among sites (Fig 4A). The similar regression for $A$. palmata for

214 the 2014-2015 interval when outplanting (as well as the bleaching event) occurred showed no

215 significant relationship (Fig 4B).

216

217 DISCUSSION:

218 This study is not intended to provide an overall cost:benefit for Acropora spp.

219 population enhancement as many details of stock collection, propagation, and short term

220 colony-scale outplant success have been previously documented (Griffin et al. 2012; Griffin et

221 al. 2015b; Johnson et al. 2011; Lirman et al. 2014; Lirman et al. 2010; Lohr et al. 2015; Mercado-

222 Molina et al. 2015; Young et al. 2012). Rather, we sought, via a low precision but large scale

223 census approach, to determine if reef-scale effects of population enhancement efforts could be

224 discerned. We performed repeated censuses over multiple reef sites over a decadal time frame

225 in which both extensive population enhancement effort and an acute thermal disturbance

226 (along with several lesser disturbances) occurred. Thus, this approach was designed to detect

227 large changes at a large spatial scale.

228 Our surface-based observation method restricted censused areas to generally less than

$2295 \mathrm{~m}$ depth. The depth of outplants at each site is not consistently documented, though some

230 were likely placed deeper than $5 \mathrm{~m}$ depths and missed in our surveys, rather than dead.

231 Although the historic core habitat of $A$. cervicornis likely extended deeper than $5 \mathrm{~m}$ depth,

232 current known distribution of $A$. cervicornis in the Keys is predominated by nearshore

233 (shallower) habitats (Miller et al. 2008) in contrast to the deeper fore-reef habitats historically 
234 described for this species. Thus, although extensive $A$. cervicornis distribution in deeper areas

235 not covered by our study is possible, current evidence does not support this in the Florida Keys.

236 Much greater overall enhancement effort ( an order of magnitude, Table 1, Suppl Table

237 1) has gone to $A$. cervicornis in comparison to A. palmata, and this added effort corresponded

238 to a significant landscape scale effect. A. cervicornis density showed a significant and positive

239 relationship with the degree of this enhancement effort across sites over the entire study

240 period (Fig 4A). However, the acute thermal bleaching event appears to have reduced the

241 impact of outplanting between 2014 and 2015 as more than double the number of outplants

242 during that year yielded a much smaller increment of density compared to the earlier interval

243 (Fig 3A). Indeed, we observed extensive bleaching and mortality of outplants during the 2014

244 bleaching event in a separate study (Miller et al., unpubl). Both the overall densities and the

245 scale of the enhancement effort have been lower for A. palmata (Table 1) which shows a clear

246 pattern of declining density over the recent decade both overall (Table 2, Fig 3B) and as

247 represented in the occupation of thickets (Fig 2). This mostly negative population trend has not

248 been substantively overcome by the small outplanting effort to date and is consistent with

249 results of independent plot-scale studies in the Florida Keys (Sutherland et al. 2016; Williams \&

250 Miller 2012). We are not aware of other published studies of contemporary trends in Florida

251 Keys $A$. cervicornis populations, although the detrimental effects of individual events on this

252 species are documented (e.g., 2010 winter cold;Kemp et al. 2011). Substantial documentation

253 does exist (Vargas-Angel et al. 2003; Walker et al. 2012)of abundant $A$. cervicornis populations,

254 including extensive thickets, in southeast Florida (over $80 \mathrm{~km}$ north of our study area), though

255 little quantitative information on trends in abundance is available in this nearby region. 
257

navigating in open ocean as well as variation in depth, visibility, and likely individual observer variation yielded less than perfect observational coverage and detection of colonies that were present. However, we implemented improved field techniques over time which improved the operational coverage of the area surveyed (e.g. the deployment of surface markers to delineate the survey area for each surveyor and the use of compasses; compare coverage of tracks in Fig $1 \mathrm{~A}$ vs 1B; additional tracks in Suppl Fig. 2). Thus, results suggesting overall decline in densities are conservative as we expect our observational detection was improved in later years. Also, this technique allowed us to evaluate population trends at a hectare scale. More resolved techniques such as photo mosaics provide a much more precise assessment technique, but are still only applicable at meso-scales (hundreds of m2; Lirman et al. 2007).

The substantial loss of $A$. palmata thicket area is a particularly concerning result.

Acropora thickets are understood to have been the typical configuration on Caribbean reefs prior to the drastic decline of these species starting in the late 1970's (Gladfelter 1982; Goreau 1959; Jaap 1984) and are functionally important in terms of providing structural habitat both for other reef inhabitants and to facilitate fragment retention (i.e., successful asexual reproduction) for the coral itself. This importance is reflected in the fact that the area of thickets (not just population abundance) has been defined as a key criterion for determining the recovery of these species under the US Endangered Species Act (NMFS 2015). The loss of $A$. palmata thicket area thus represents a trend opposing species recovery. The density of all $A$. palmata colonies also shows negative trends at most sites, both before and during the acute thermal bleaching event (Table 1). 

outplanting effort (predominantly during a bleaching year) did not appear to be adequate to produce a similar relationship for A. palmata. Also, positive effects of outplanting $A$. cervicornis appeared to be damped by a massive thermal stress event in 2014-15. If the intent is to recover these foundation species (as mandated by the Endangered Species Act) and maintain reef ecosystem function, our results point to the need for ongoing population enhancement efforts as a stop-gap strategy to prevent further population declines while the paramount need to curtail climate change is addressed (NMFS 2015).

ACKNOWLEDGEMENTS: Field assistance by KL Kramer, A Valdivia, AJ Bright, RE Pausch, L preparation. The Coral Restoration Foundation graciously provided information on total population enhancement effort by reef. 


\section{REFERENCES}

Acropora Biological Review Team. 2005. Atlantic Acropora Status Review Document. Report to National Marine Fisheries Service, Southeast Regional Office. p 152 pp.

http://sero.nmfs.noaa.gov/protected_resources/coral/elkhorn_coral/document/Key_Docs/200 4 status review.pdf.

Aronson RB, and Precht WF. 2001. White-band disease and the changing face of Caribbean coral reefs. Hydrobiologia 460:25-38.

Bright A, Williams DE, and Miller MW. 2013. Recovery of Acropora palmata in Curaçao: a comparison with the Florida Keys. Bulletin of Marine Science 89:747-757.

Devine B, Rogers CS, and Loomis C. 2005. Mapping marine populations: using surface water GPS for spatial analysis. Proceedings of the Gulf and Caribbean Fisheries Institute 56:411-420.

Epstein N, Bak RPM, and Rinkevich B. 2003. Applying forest restoration principles to coral reef rehabilitation. Aquatic Conservation: marine and freshwater ecosystems 13:387-395.

Gladfelter WB. 1982. White-Band Disease in Acropora palmata : Implications for the structure and growth of shallow reefs. Bulletin of Marine Science 32:639-643.

Goreau TF. 1959. The ecology of Jamaican coral reefs: I. species composition and zonation. Ecology 40:67-90.

Griffin JN, Schrack EC, Lewis K-A, Baums IB, Soomdat N, and Silliman BR. 2015a. Density-dependent effects on initial growth of a branching coral under restoration. Restoration Ecology 23:197-200.

Griffin S, Spathias H, Moore T, Baums I, and Griffin B. 2012. Scaling up Acropora nurseries in the Caribbean and improving techniques. Proceedings of the 12th International Coral Reef Symposium. p 1-5.

Griffin SP, Nemeth MI, Moore TD, and Gintert B. 2015b. Restoration using Acropora cervicornis at the T/V MARGARA grounding site. Coral Reefs.

Jaap WC. 1984. The ecology of the south Florida coral reefs: a community profile: US Fish and Wildlife Service, FWS/OBS-82/08.

Johnson ME, Lustic C, Bartels E, Baums IB, Gilliam DS, Larson L, Lirman D, Miller MW, Nedimyer K, and Schopmeyer S. 2011. Caribbean Acropora Restoration Guide: Best Practices for Propagation and Population Enhancement Arlington, VA.: The Nature Conservancy. p 54.

Kemp DW, Oakley CA, Thornhill DJ, Newcomb LA, Schmidt GW, and Fitt WK. 2011. Catastrophic mortality on inshore coral reefs of the Florida Keys due to severe low-temperature stress. Global Change Biology 17:3468-3477.

Lidz BH, Reich CD, Peterson RL, and Shinn EA. 2006. New Maps, New Information: Coral Reefs of the Florida Keys. Journal of Coastal Research:260-282.

Lirman D, Gracias NR, Gintert BE, Gleason ACR, Reid RP, S. N, and P. K. 2007. Development and application of a video-mosaic survey technology to document the status of coral reef communities. Environmental Monitoring and Assessment 125:59-73.

Lirman D, Schopmeyer S, Galvan V, Drury C, Baker AC, and Baums IB. 2014. Growth Dynamics of the Threatened Caribbean Staghorn Coral <italic >Acropora cervicornis</italic>: Influence of Host Genotype, Symbiont Identity, Colony Size, and Environmental Setting. PLOS ONE 9:e107253.

Lirman D, Thyberg T, Herlan J, Hill C, Young-Lahiff C, Schopmeyer S, Huntington B, Santos R, and Drury C. 2010. Propagation of the threatened staghorn coral Acropora cervicornis: methods to minimize the impacts of fragment collection and maximize production. Coral Reefs 29:729-735.

Lohr KE, Bejarano S, Lirman D, Schopmeyer S, and Manfrino C. 2015. Optimizing the productivity of a coral nursery focused on staghorn coral Acropora cervicornis. Endangered Species Research 27:243-250. 
Marszalek DS. 1977. Florida reef tract marine habitats and ecosystems: Maps published in cooperation with State of Florida Department of Natural Resources. . New Orleans Outer Continental Shelf Office: US Department of Interior Bureau of Land Management

Mercado-Molina AE, Ruiz-Diaz CP, and Sabat AM. 2015. Demographics and dynamics of two restored populations of the threatened reef-building coral Acropora cervicornis. Journal for Nature Conservation 24:17-23.

Miller MW. 2008. Acropora Spatial Survey Data of the Upper Florida Keys National Marine Sanctuary 2005 -2007. (NODC Accession 0046934). . NMFS InPort Catalog ID \# 24327; https://inport.nmfs.noaa.gov/inport/item/24327.

Miller MW, Lohr KE, Cameron CM, Williams DE, and Peters EC. 2014. Disease dynamics and potential mitigation among restored and wild staghorn coral, Acropora cervicornis. PeerJ 2:e541.

Miller SL, Chiappone M, Rutten LM, and Swanson DW. 2008. Population status of Acropora corals in the Florida Keys. Proceedings of the 11th International Coral Reef Symposium 2: 781-785

NMFS. 2015. Recovery Plan for Elkhorn (Acropora palmata) and Staghorn (A.cervciornis) Corals. Prepared by the Acropora Recovery Team for the National Marine Fisheries Service. Silver Spring, Maryland.

Rinkevich B. 2015. Climate Change and Active Reef Restoration-Ways of Constructing the "Reefs of Tomorrow". Journal of Marine Science and Engineering 3:111-127.

Schopmeyer SA, and Lirman D. 2015. Occupation Dynamics and Impacts of Damselfish Territoriality on Recovering Populations of the Threatened Staghorn Coral, Acropora cervicornis. PLOS ONE 10:e0141302.

Sutherland KP, Berry B, Park A, Kemp DW, Kemp KM, Lipp EK, and Porter JW. 2016. Shifting white pox aetiologies affecting Acropora palmata in the Florida Keys, 1994-2014. Philosophical Transactions of the Royal Society of London B: Biological Sciences 371.

Vargas-Angel B, Thomas JD, and Hoke SM. 2003. High-latitude Acropora cervicornis thickets off Fort Lauderdale, Florida, USA. Coral Reefs 22:465-473.

Walker BK, Larson EA, Moulding AL, and Gilliam DS. 2012. Small-scale mapping of indeterminate arborescent acroporid coral (Acropora cervicornis) patches. Coral Reefs 31:885-894.

Williams DE. 2013. CRCP-Acropora spp. distribution in the upper Florida Keys 2013-2015. NMFS InPort Catalog ID\# 26791; https://inport.nmfs.noaa.gov/inport/item/26791.

Williams DE, and Miller MW. 2012. Attributing mortality among drivers of population decline in Acropora palmata in the Florida Keys (USA). Coral Reefs 31:369-382.

Young CN, Schopmeyer SA, and Lirman D. 2012. A review of reef restoration and coral propagation using the threatened genus Acropora in the Caribbean and Western Atlantic. Bulletin of Marine Science 88:1075-1098. 
376 Figure Legends:

377 Fig 1: Component maps and spatial analyses are illustrated for a single site (Grecian Rocks) and 378 interval. A similar sequence of maps was constructed for each site (Supplemental Fig 1,2) and

379 temporal comparison. Observed search tracks and waypoint features mapped for each census

380 year are given in A) 2006 with waypoints as stars and B) 2014 with waypoints as asterisks. A.

381 palmata colony waypoints are depicted in yellow, $A$. cervicornis colonies in purple, and $A$.

382 palmata thicktet outline points in red. C) Merged maps for temporal comparison showing the 383 congruent observed area (determined by GIS intersect of the polygons determined by the 384 search tracks for each year) for both years and the overlayed colony distribution observed in 385 both years. Similar year and temporal comparison maps for 2014-2015 are given in 386 Supplemental Fig 2).

387 Fig 2: Area $\left(\mathrm{m}^{2}\right)$ of A.palmata thickets (i.e. high density aggregations for which mapping 388 individual colonies was deemed infeasible) at four sites over time. Horseshoe was surveyed in 389 both 2005 and 2007 so the point for this time period is a mean of these two. Thickets dropping to zero area likely still contained remnant colonies, but at lower densities such that individual

391 colonies could be mapped (see text for details on methods).

392 Fig 3: Annualized proportional change in colony density (i.e., proportion change from Table 1 divided by the number of years in the observed interval; mean plus $1 \mathrm{SE}$ ) for Acropora cervicornis (A) and Acropora palmata (B) during two time intervals. Diamonds (right y-axis)

395 show the mean number of fragments of each species outplanted per year over the same 396 intervals. Note the differences in axis scales. 
397 Fig 4: Scatterplot showing linear regressions for proportional change in colony density relative 398 to the cumulative number of outplants for A) Acropora cervicornis (full interval of observation, $399 \mathrm{n}=14$ sites) and B) Acropora palmata. Population enhancement has only occurred for 400 A.palmata since 2014 , so B) shows proportional change in density for this species from 20144012015 at $n=9$ sites (regression is not significant).

402 


\section{Figure 1}

Illustration of survey and spatial analysis

Component maps and spatial analyses are illustrated for a single site, Grecian Rocks; a similar sequence of maps was constructed for each site (given in Supplemental Fig 1) and temporal comparison. Observed search tracks and waypoint features mapped for each census year (2006 points as stars, 2014 points as asterisks) are given in A) 2006 with waypoints as stars and B) 2014 with waypoints as asterisks. A. palmata colony waypoints are depicted in yellow, A. cervicornis colonies in purple, and $A$. palmata thicktet outline points in red. C) Merged maps for temporal comparison showing the congruent observed area (determined by GIS intersect of the polygons determined by the search tracks for each year) for both years and the overlayed colony distribution observed in both years. Similar year and temporal comparison maps for 20142015 are given in Supplemental Fig 2).
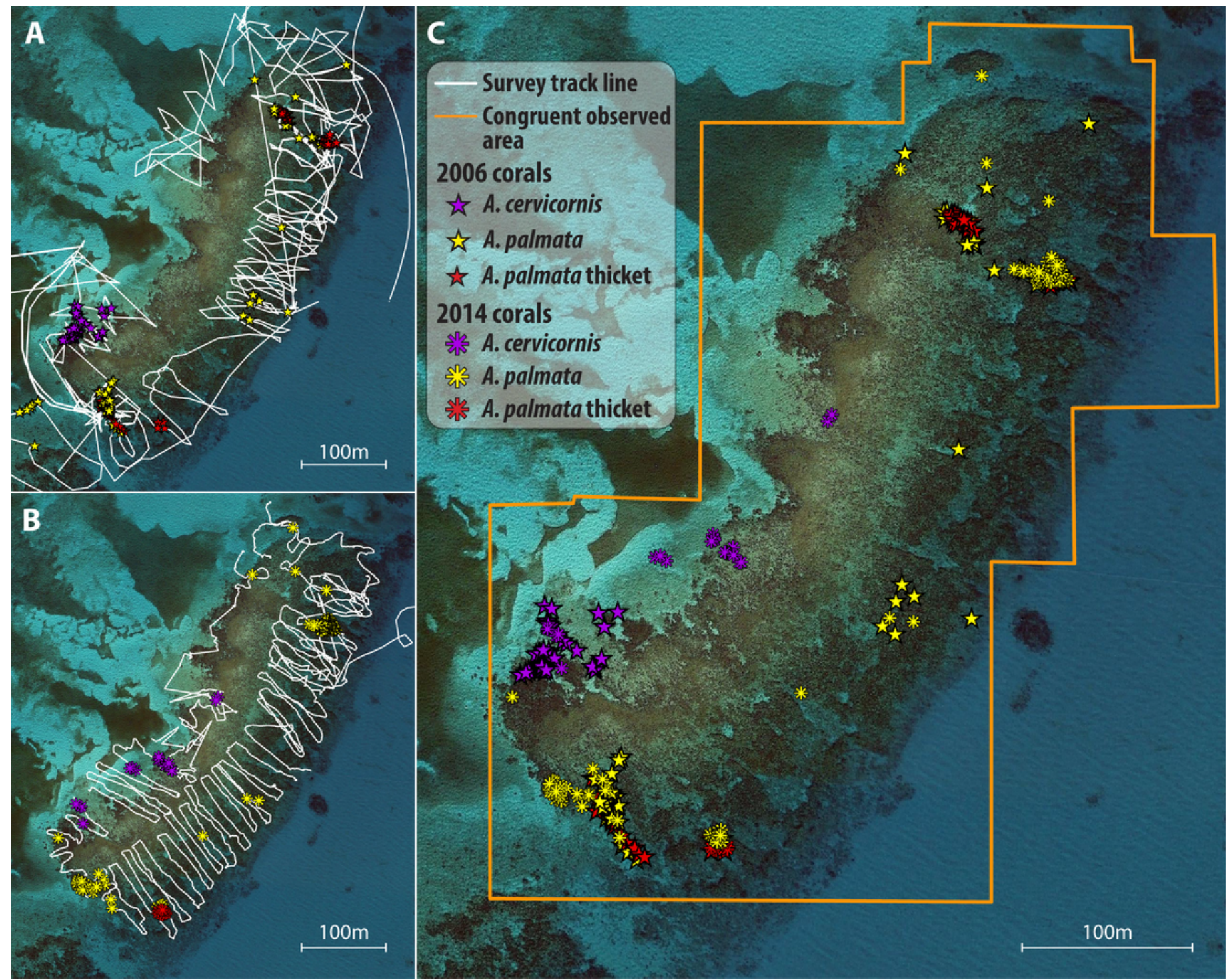
Figure 2 (on next page)

Acropora palmata thickets

Area $\left(\mathrm{m}^{2}\right)$ of $A$.palmata thickets (i.e. high density aggregations for which mapping individual colonies was deemed infeasible) at four sites over time. Horseshoe was surveyed in both 2005 and 2007 so the point for this time period is a mean of these two. Thickets dropping to zero area likely still contained remnant colonies, but at lower densities such that individual colonies could be mapped (see text for details on methods). 


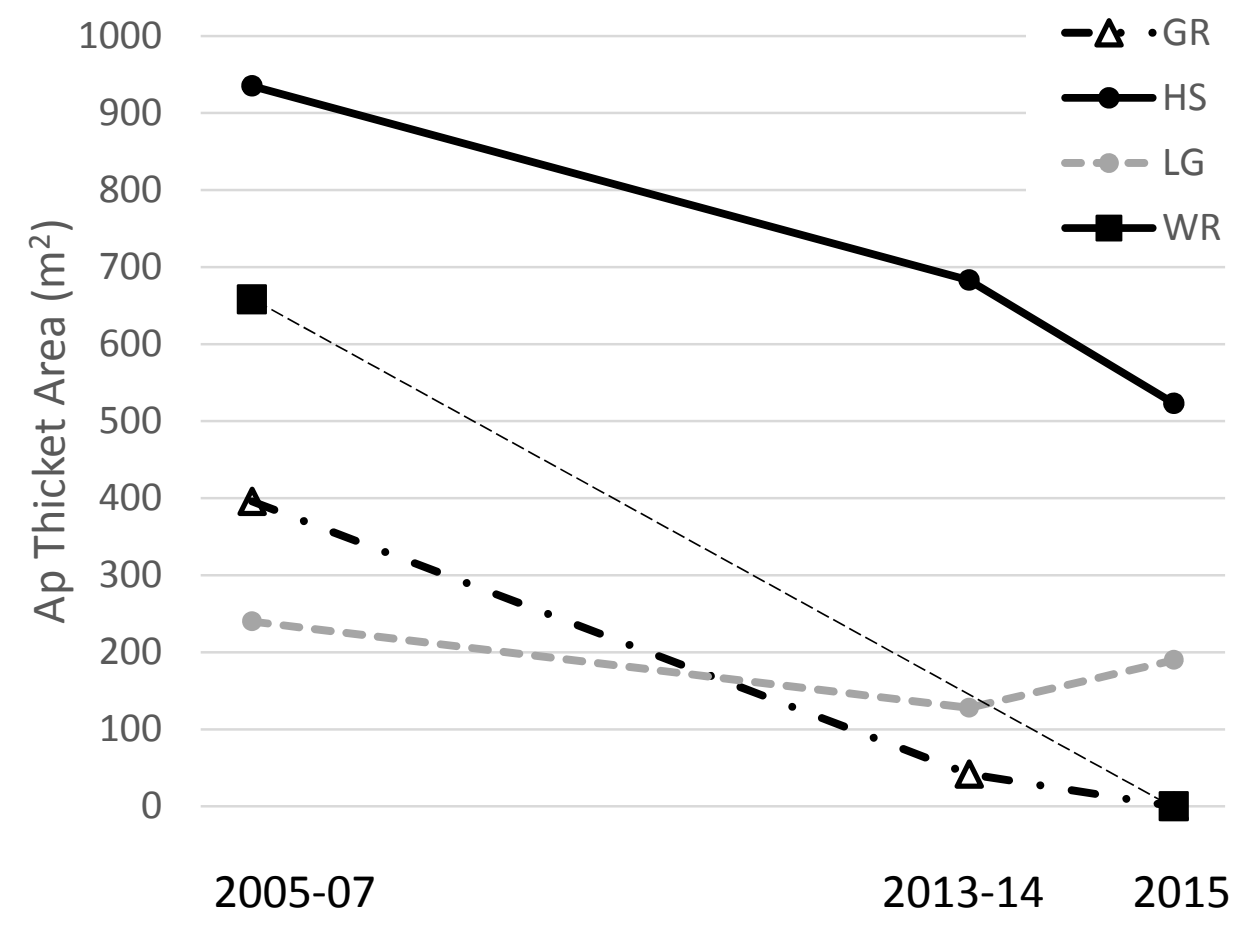


Figure 3 (on next page)

Acropora spp. change in density

Annualized proportional change in colony density (i.e., proportion change from Table 1 divided by the number of years in the observed interval; mean plus 1 SE) for Acropora cervicornis (A) and Acropora palmata (B) during two time intervals. Diamonds (right y-axis) show the mean number of fragments of each species outplanted per year over the same intervals. Note the differences in axis scales. 
A) A.cervicornis

5.0

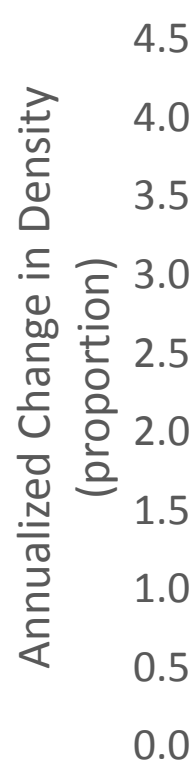

3000

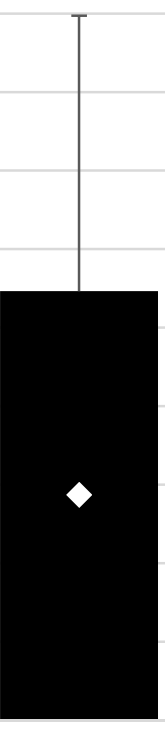

2005-14
2500

$\diamond$
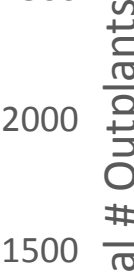

1000

500

0

B) A.palmata

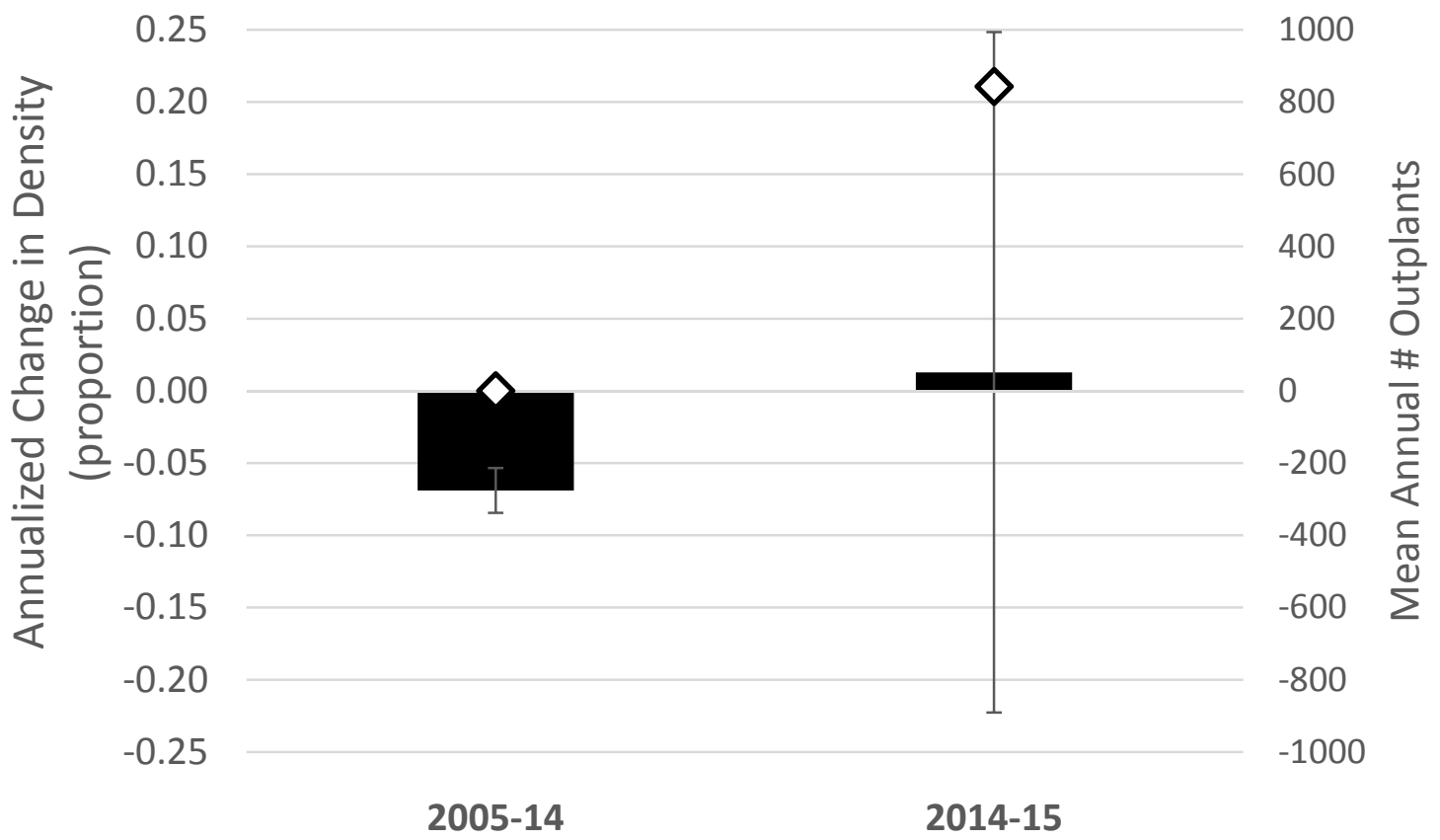


Figure 4 (on next page)

Acropora spp change in colony density with population enhancement

Scatterplot showing linear regressions for proportional change in colony density relative to the cumulative number of outplants for A) Acropora cervicornis (full interval of observation, $\mathrm{n}=14$ sites) and B) Acropora palmata. Population enhancement has only occurred for $A$. palmata since 2014, so B) shows proportional change in density for this species from 20142015 at $n=9$ sites (regression is not significant). 
A) A. cervicornis, $2005-2015$

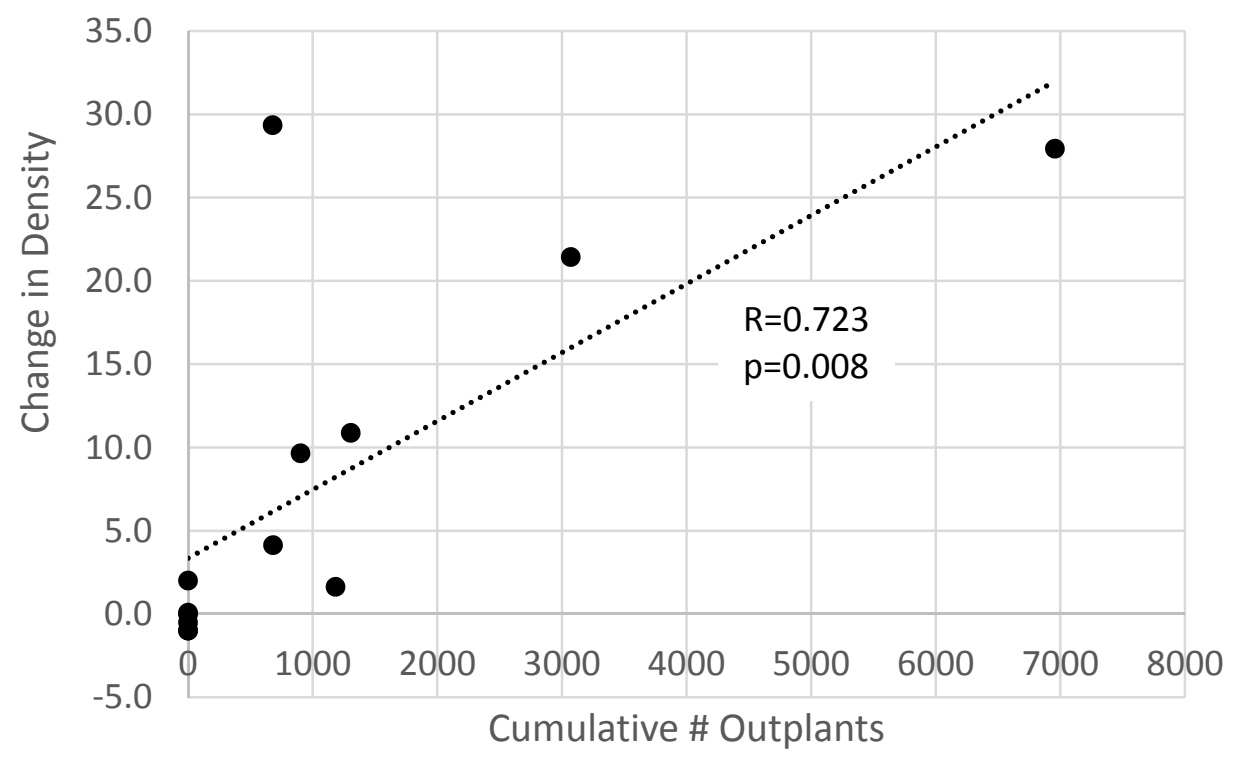

B) A. palmata, $2014-2015$

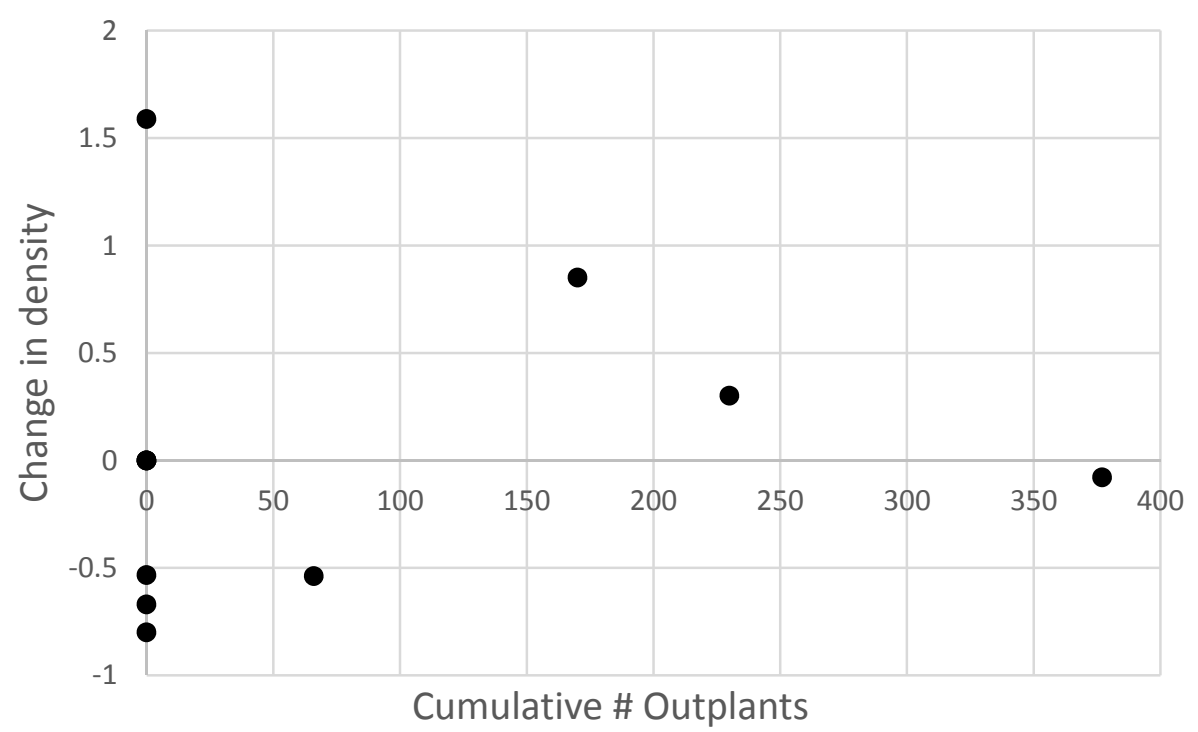




\section{Table $\mathbf{1}$ (on next page)}

Long-term and short-term Acropora spp. changes at sites in the upper Florida Keys.

Summary of congruent observed areas, colony densities, and number of outplants for both species over A) long term interval prior to 2014 thermal bleaching event and B) over the 2014-2015 bleaching event, at sites in the upper Florida Keys. Change in density is represented as a proportion of the initial density. Information on numbers of outplants provided by Coral Restoration Foundation, the only organization performing large-scale population enhancement in this region. 'Early' and 'Late' refer to the first and last survey year, respectively, of the interval for each site. $C F=$ Carysfort, $F R=$ French, $M L=$ Molasses, $\mathrm{NDR}=$ North Dry Rocks, WBDR1/2= White Bank Dry Rocks north/south, $\mathrm{LG}=$ Little Grecian, $\mathrm{GR}=$ Grecian Rocks, NNDR $=$ North North Dry Rocks, SI= Sand Island 


\begin{tabular}{|c|c|c|c|c|c|c|c|c|c|c|c|c|c|c|}
\hline A) & & & A. ce & vicornis & & & & & A. palr & mata & & & & \\
\hline Reef & Years & $\begin{array}{l}\text { Congr } \\
\text { Area (ha) }\end{array}$ & $\begin{array}{l}\text { \#Ac- } \\
\text { Early }\end{array}$ & $\begin{array}{l}\text { AcDens } \\
\text {-Early }\end{array}$ & $\begin{array}{l}\text { \#Ac- } \\
\text { Late }\end{array}$ & $\begin{array}{l}\text { AcDens- } \\
\text { Late }\end{array}$ & $\begin{array}{l}\text { Change } \\
\text { AcDens }\end{array}$ & \begin{tabular}{|l} 
\# Ac \\
Outpl
\end{tabular} & $\begin{array}{l}\text { \#Ap- } \\
\text { Early }\end{array}$ & \begin{tabular}{|l|} 
ApDens- \\
Early
\end{tabular} & $\begin{array}{l}\text { \#Ap- } \\
\text { Late }\end{array}$ & $\begin{array}{l}\text { ApDense- } \\
\text { Late }\end{array}$ & $\begin{array}{l}\text { Change } \\
\text { ApDens }\end{array}$ & $\begin{array}{l}\# \text { Ap } \\
\text { Outpl }\end{array}$ \\
\hline $\mathrm{CF}$ & $05 \& 14$ & 1.6 & 8 & 4.9 & 9 & 5.6 & 0.1 & 370 & 55 & 34.0 & 0 & 0.0 & -1.0 & 0 \\
\hline$F R$ & $07 \& 14$ & 8.0 & 8 & 1.0 & 41 & 5.1 & 4.1 & 682 & 185 & 23.2 & 63 & 7.9 & -0.7 & 0 \\
\hline$\overline{M L}$ & $06 \& 14$ & 15.5 & 12 & 0.8 & 1331 & 85.8 & 109.9 & 3071 & 239 & 15.4 & 89 & 5.7 & -0.6 & 0 \\
\hline NDR & $06 \& 14$ & 3.9 & 109 & 28.3 & 3 & 0.8 & -1.0 & 300 & 74 & 19.2 & 27 & 7.0 & -0.6 & 50 \\
\hline$\overline{G R}$ & $06 \& 14$ & 14.1 & 42 & 3.0 & 39 & 2.8 & -0.1 & 0 & 408 & 29.0 & 276 & 19.6 & -0.3 & 0 \\
\hline WBDR 2 & $06 \& 14$ & 6.4 & 10 & 1.6 & 526 & 82.3 & 51.6 & 1307 & 0 & 0.0 & 0 & 0.0 & 0.0 & 0 \\
\hline WBDR 1 & $06 \& 14$ & 9.3 & 172 & 18.6 & 448 & 48.4 & 1.6 & 0 & 6 & 0.6 & 0 & 0.0 & -1.0 & 0 \\
\hline LG & $06 \& 13$ & 2.1 & 1 & 0.5 & 8 & 3.8 & 7.0 & 0 & 320 & 153.8 & 270 & 129.8 & -0.2 & 0 \\
\hline
\end{tabular}

\begin{tabular}{|c|c|c|c|c|c|c|c|c|c|c|c|c|c|c|}
\hline B) & & & A.cer & icornis & & & & & A. pa & mata & & & & \\
\hline Reef & Years & $\begin{array}{l}\text { Congr } \\
\text { Area (ha) }\end{array}$ & $\begin{array}{l}\text { \#Ac- } \\
\text { Early }\end{array}$ & $\begin{array}{l}\text { AcDens } \\
\text { Early }\end{array}$ & $\begin{array}{l}\text { \#Ac- } \\
\text { Late }\end{array}$ & $\begin{array}{l}\text { AcDens } \\
\text { Late }\end{array}$ & $\begin{array}{l}\text { Change } \\
\text { AcDens }\end{array}$ & $\begin{array}{l}\text { \#Ac } \\
\text { Outpl }\end{array}$ & $\begin{array}{l}\text { \#Ap- } \\
\text { Early }\end{array}$ & \begin{tabular}{|l} 
Ap Dens \\
Early
\end{tabular} & $\begin{array}{l}\text { \#Ap- } \\
\text { Late }\end{array}$ & $\begin{array}{l}\text { ApDense } \\
\text { Late }\end{array}$ & $\begin{array}{l}\text { Change } \\
\text { ApDens }\end{array}$ & $\begin{array}{l}\text { \#Ap } \\
\text { Outpl }\end{array}$ \\
\hline $\mathrm{CF}$ & $14 \& 15$ & 9.4 & 0 & 0.0 & 0 & 0.0 & 0.0 & 815 & 26 & 2.8 & 12 & 1.3 & -0.5 & 66 \\
\hline$F R$ & $14 \& 15$ & 7.3 & 40 & 5.5 & 102 & 13.9 & 1.6 & 0 & 63 & 8.6 & 82 & 11.2 & 0.3 & 230 \\
\hline$\overline{M L}$ & $14 \& 15$ & 13.5 & 1260 & 93.2 & 269 & 19.9 & -0.8 & 915 & 89 & 6.6 & 82 & 6.1 & -0.1 & 377 \\
\hline NDR & $14 \& 15$ & 3.1 & 109 & 34.7 & 79 & 25.2 & -0.3 & 388 & 74 & 23.6 & 137 & 43.6 & 0.9 & 170 \\
\hline $\mathrm{GR}$ & $14 \& 15$ & 9.3 & 39 & 4.2 & 231 & 24.8 & 4.9 & 603 & 241 & 25.9 & 50 & 5.4 & -0.8 & $\overline{0}$ \\
\hline WBDR2 & $14 \& 15$ & 5.6 & 526 & 93.4 & 194 & 34.5 & -0.6 & 0 & $\overline{0}$ & 0.0 & $\overline{0}$ & 0.0 & $\overline{0}$ & $\overline{0}$ \\
\hline WBDR1 & $14 \& 15$ & 6.2 & 446 & 71.7 & 84 & 13.5 & -0.8 & 0 & $\overline{0}$ & 0.0 & $\overline{0}$ & 0.0 & $\overline{0}$ & 0 \\
\hline NNDR & $13 \& 15$ & 2.6 & 8 & 3.1 & 0 & 0.0 & -1.0 & 0 & 34 & 13.0 & 88 & 33.7 & 1.6 & 0 \\
\hline$\overline{L G}$ & $13 \& 15$ & 3.5 & 18 & 5.1 & 15 & 4.3 & -0.2 & 0 & 60 & 17.1 & 28 & 8.0 & -0.5 & 0 \\
\hline $\mathrm{SI}$ & $14 \& 15$ & 3.5 & 0 & 0.0 & 0 & 0.0 & 0.0 & 0 & 106 & 30.7 & 35 & 10.1 & -0.7 & 0 \\
\hline
\end{tabular}




\section{Table 2 (on next page)}

Overall changes in colony density

Cumulative changes in Acropora spp. colony density over the full study duration (2005-07 versus 2014-15) pooled among sites with and without outplanting for each species. Sites and specific durations for each given in Suppl Table 2. 
1 Table 2: Cumulative changes in Acropora spp. colony density over the full study duration (2005-

207 versus 2014-15) pooled among sites with and without outplanting for each species. Sites

3 and specific durations for each given in Suppl Table 2.

4

\begin{tabular}{|c|c|c|c|c|c|c|}
\hline & $\begin{array}{l}\text { Total Congr } \\
\text { area (ha) }\end{array}$ & $\begin{array}{l}\text { \# colonies } \\
\text { early }\end{array}$ & $\begin{array}{l}\text { Density } \\
\text { early }\end{array}$ & $\begin{array}{l}\text { \# colonies } \\
\text { late }\end{array}$ & $\begin{array}{l}\text { Density } \\
\text { late }\end{array}$ & $\begin{array}{l}\text { Change in } \\
\text { density }\end{array}$ \\
\hline \multicolumn{7}{|l|}{ A. cervicornis } \\
\hline $\begin{array}{l}\text { With Outplants } \\
\text { ( } n=7 \text { sites) }\end{array}$ & 50.8 & 93 & 1.8 & 1356 & 26.7 & 13.6 \\
\hline $\begin{array}{l}\text { Without Outplants } \\
\text { ( } n=7 \text { sites) }\end{array}$ & 33.2 & 227 & 6.8 & 144 & 4.3 & -0.4 \\
\hline \multicolumn{7}{|l|}{ A. palmata } \\
\hline $\begin{array}{l}\text { With Outplants } \\
\text { ( } n=5 \text { sites) }\end{array}$ & 33.8 & 620 & 18.3 & 369 & 10.9 & -0.4 \\
\hline $\begin{array}{l}\text { Without Outplants } \\
\text { ( } n=9 \text { sites) }\end{array}$ & 50.2 & 671 & 13.4 & 178 & 3.5 & -0.7 \\
\hline
\end{tabular}

5 